
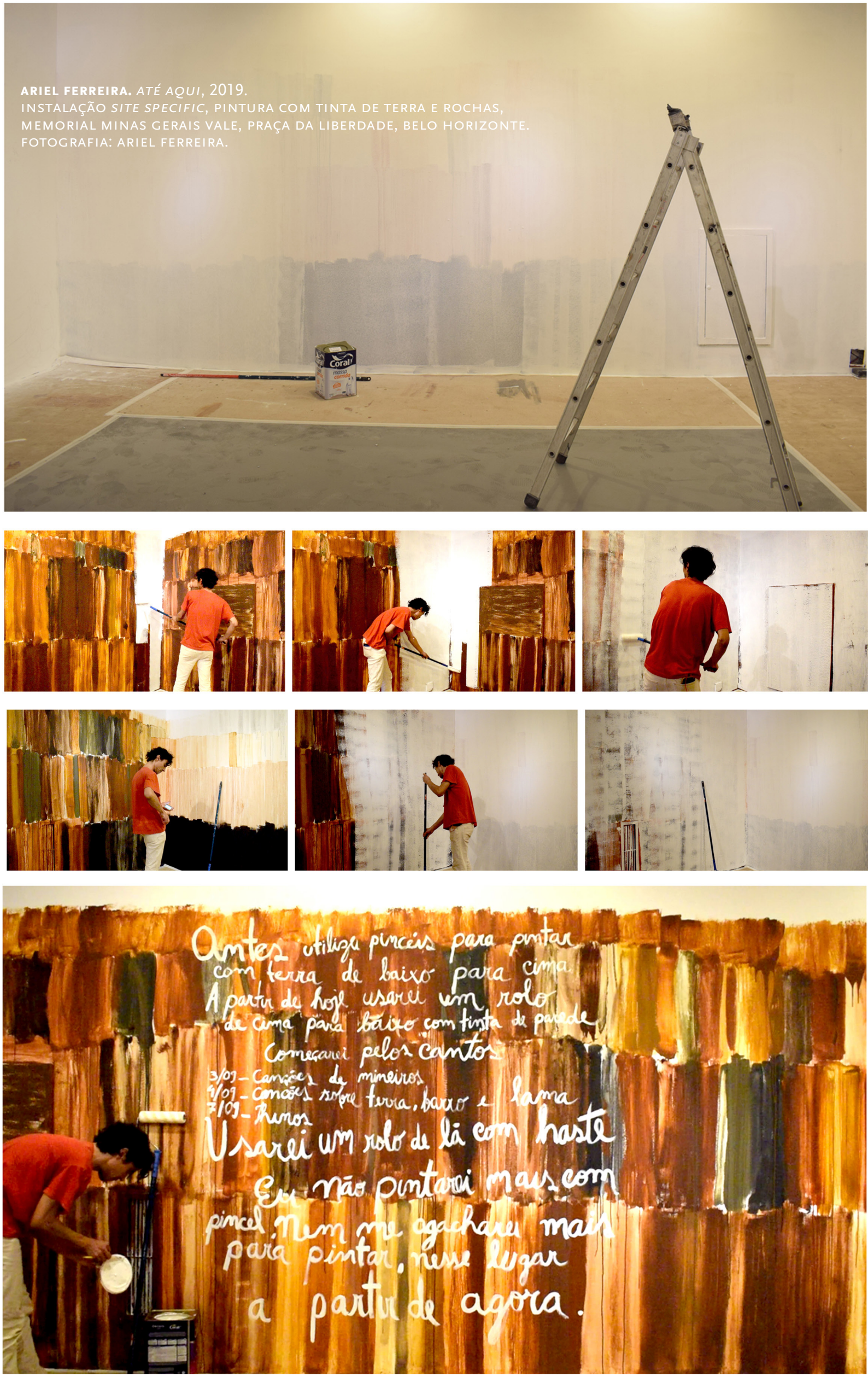


\section{MINERODUTOS E}

IMPLICAÇÕES SOCIOAMBIENTAIS:

PANORAMA LEGAL E REFLEXÕES

PARA O CENÁRIO DE MINAS

\section{GERAIS}

ANTÔNIO PEREIRA MAGALHÃES JÚNIOR**

REGINA PAULA BENEDETTO DE CARVALHO*

DANIEL MACHADO FACURY*

Gabriel Andrade Camilo**

Giovanna Soares Ramanery*:

RESUMO Minerodutos são considerados modais de transporte dentre os mais eficientes em termos de logística, mas a sua instalação e funcionamento podem trazer impactos, conflitos e desastres socioambientais como os riscos de escassez hídrica, por exemplo. No Brasil, a maior parte dos minerodutos está em Minas Gerais, estado com tradicional atividade minerária. Este artigo busca apresentar um panorama dos minerodutos em Minas Gerais e de suas implicações socioambientais, particularmente nos recursos hídricos. Foi realizada análise documental dos minerodutos instalados e projetados, a legislação, a repercussão na mídia e potenciais conflitos gerados por essas estruturas. São destacadas maiores incongruências durante as negociações de terras e licenciamento; durante a instalação dos minerodutos, sobre alterações na paisagem; e durante a operação, quanto ao uso da água; além de implicações políticas e econômicas de escala regional. PALAVRAS-CHAVE Mineração. Transporte de rejeitos. Segurança hídrica.

\section{ORE SLURRY PIPELINES AND SOCIO-ENVIRONMENTAL ASPECTS IN MINAS GERAIS STATE: LEGAL OVERVIEW AND REFLECTIONS ABOUT THE MINAS GERAIS’ SCENARIO}

ABSTRACT Ore slurry pipelines are considered transport modes among the most efficient in terms of logistics, but their installation and operation can bring socio-environmental impacts, conflicts and disasters as, for example, the risks of water scarcity. In Brazil, most of the pipelines are in Minas Gerais, a state with traditional mining activity. This article seeks to present an overview of the pipelines in Minas Gerais and their socio-environmental implications, particularly on water resources. Documentary analysis of the installed and projected pipelines, legislation, repercussions in the media and potential conflicts were carried out. Major inconsistencies are highlighted during land and licensing negotiations, during the installation of the pipelines, about changes in the landscape, and during the operation, regarding the use of water, as well as political and economic implications on a regional scale.

KEYWORDS Mining. Ore transport modes. Water security.

* Instituto de Geociências, Universidade Federal de Minas Gerais (UFMG). 


\section{Introdução}

$\mathrm{E}$ m um país de dimensão continental como o Brasil os modais de transporte são estruturas essenciais e estratégicas para a integração de seu território. Tendo em vista que grande parte da economia brasileira gira em torno da exportação de commodities através das zonas portuárias, as dutovias respondem por boa parte do escoamento de recursos como óleo, gás e minérios. Os dutos que transportam minérios são construídos e geridos por empresas privadas para atender aos interesses logísticos das atividades de mineração. Apesar do alto custo inicial de implantação, a capacidade de carga transportada e o custo de manutenção garantem o retorno do valor investido nas dutovias (PESSOA, 20I6; MTPA, 2018).

No Brasil, a maior parte dos complexos minerários de grande porte está distante das zonas portuárias, como é o caso de Minas Gerais, fazendo com que os minerodutos sejam, em geral, a melhor opção em termos econômicos para empreendimentos de grande porte. Além disso, autores como Pessoa (20I6) apontam que os minerodutos geram impactos menos significativos em relação a outros modais e apresentam outras vantagens, que se estendem a questões estratégicas relativas à produção, logística e geração de empregos.

No entanto, apesar das vantagens supracitadas, não se pode menosprezar a prer-

1 Desastres são o resultado da ocorrência de eventos adversos de origem natural ou humana em cenários de vulnerabilidade, acarretando, portanto, prejuízos e danos sociais, ambientais, econômicos e/ ou materiais ao patrimônio público e privado (CEPED/ RS-UFRGS, 2016). rogativa das conexões entre os impactos causados por minerodutos e o aumento das ameaças de desastres ${ }^{\mathrm{I}}$ socioambientais, principalmente em decorrência da degradação de recursos hídricos e risco de desabastecimento de municípios, gerando tensões territoriais. Os traçados dos dutos e a utilização de água no escoamento de minério podem gerar processos de supressão de nascentes e alteração da dinâmica fluvial, reduzindo a quantidade e, muitas vezes, a qualidade das águas apropriadas por outros usuários. Outros impactos relativos à segurança hídrica estão associados às alterações no relevo, à supressão de vegetação nativa e à intensificação de processos erosivos. Já no meio social, as obras podem levar ao aumento de contingente populacional e serviços nos 
municípios envolvidos, pressionando os sistemas hídricos (BRANDT, 2006). Essas questões não são consensuais e geram conflitos de interesses entre o poder público, o setor privado e a sociedade civil, nas esferas federal, estadual e municipal.

Este trabalho insere-se nesse contexto de estudos sobre os riscos de desastres das atividades minerarias à qualidade do patrimônio socioambiental do país, ainda que não nos esqueçamos dos inegáveis benefícios que o setor proporciona. O objetivo é apresentar um panorama dos minerodutos em Minas Gerais e de suas implicações socioambientais, particularmente no que tange aos recursos hídricos. Para isso, foi realizada a sistematização e análise dos principais aspectos legais envolvidos no processo de licenciamento de grandes projetos minerários em Minas Gerais, junto aos impactos e principais conflitos derivados.

\section{Procedimentos metodológicos}

A pesquisa foi embasada pelo levantamento, sistematização e análise de dados e informações oficiais e de livre acesso sobre o arcabouço legislativo, licenciamento, estudos e relatórios de impactos ambientais (EIA/RIMAs) relativos aos minerodutos (instalados ou em perspectiva) em Minas Gerais. As consultas também envolveram artigos, relatórios técnicos e notícias relativas ao poder público e ao setor mineral como um todo.

Em termos federais, as informações foram obtidas principalmente dos sites das seguintes instituições: Ministério do Meio Ambiente (MMA), Instituto Brasileiro do Meio Ambiente e dos Recursos Naturais Renováveis (IBAMA), Agência Nacional de Transportes Terrestres (ANTT), Agência Nacional de Águas (ANA), Agência Nacional de Mineração (ANM), Sistema Nacional de Informações sobre Saneamento (SNIS) e catálogo online do Sistema de Bibliotecas da Universidade Federal de Minas Gerais. No âmbito estadual, destacaram-se os sites do Sistema Estadual do Meio Ambiente e Recursos Hídricos (SISEMA), do Instituto Mineiro de Gestão das Águas (IGAM) e da Assembleia Legislativa do Estado de Minas Gerais (ALMG).

Em uma perspectiva dialética, a análise buscou elencar: (i) elementos históricos, econômicos e políticos, que estimularam (e estimulam) a instalação de minerodutos em MG; (ii) procedimentos legais para concessão das licenças (prévia, instalação e 
operação), pelas quais são deliberados os estudos ambientais necessários a essas concessões; (iii) a identificação dos impactos ambientais e sociais, a partir dos estudos ambientais legalmente exigidos, relacionados principalmente à degradação dos recursos hídricos; e (iv) casos de práticas políticas e de negociação abusiva entre empresas e proprietários de terra que causaram (ou ainda causam) tensões territoriais. As informações permitiram o confronto das ideias e a concepção de reflexões com base em diferentes elementos naturais e sociais interligados. Esse enredamento busca instigar a percepção do leitor sobre as relações de causa-efeito que se processam como consequência de projetos de minerodutos, as quais tendem a tornar-se mais complexas ao longo dos processos de instalação e operação dos empreendimentos. São gerados, portanto, diferentes cenários de impactos e conflitos territoriais, principalmente em função da ameaça à segurança hídrica.

Além da análise documental, foram executados procedimentos de análise espacial para gerar um mapa síntese com a origem, rota e local de escoamento dos minerodutos estudados. Os dados georreferenciados, com os traçados dos minerodutos, foram adquiridos pelo banco de dados do site da ANTT (20I9) e de outras bases geográficas utilizadas para criar referências espaciais, como limites administrativos de estados e municípios O mapa foi elaborado com o uso do software de geoprocessamento ArcGIS (versão I0.5.I). Outra análise espacial foi realizada por meio de imagens de satélite do software Google Earth, visando identificar e ilustrar possíveis alterações morfológicas causadas pela instalação de minerodutos, o que foi exemplificado pelo mineroduto Minas-Rio (empresa Anglo American), na região da Zona da Mata mineira.

\section{Aspectos legais e atual contexto das políticas de regulamentação de minerodutos em Minas Gerais}

O processo de licenciamento de minerodutos compete a órgãos federais, estaduais e municipais, de acordo com a dimensão territorial do projeto, junto aos processos de concessão de lavra e beneficiamento. Os trâmites envolvem diferenças de competências em função de sua abrangência territorial. Assim, ainda que um empreendimento 
minerário situado em Minas Gerais esteja atrelado a um mineroduto que abranja mais de um estado, a atividade da mina é licenciada pela Secretaria de Meio Ambiente e Desenvolvimento Sustentável (SEMAD). No entanto, a atividade do mineroduto em si deve ser licenciada pelo IBAMA (órgão federal) já que, conforme o artigo Io da Lei $\mathrm{N}^{\mathrm{o}}$ 6.938, de 3i de agosto de i981, que estabelece a Política Nacional do Meio Ambiente - PNMA (BRASIL, I98I), compete ao IBAMA o licenciamento de minerodutos em caráter supletivo à atuação do órgão ambiental estadual, pelo fato de seus impactos e atividades serem de âmbito interestadual.

De acordo com a Lei no 6.938/8I e outros documentos normativos específicos, os minerodutos podem gerar considerável impacto ambiental por sua natureza e porte, sendo, portanto, passíveis de Estudo de Impacto Ambiental e respectivo Relatório de Impacto Ambiental - EIA/RIMA, condicionados à aprovação do IBAMA (BRASIL, I98I). Cabe ao poder público estadual e municipal a complementação dos estudos técnicos solicitados pelo IBAMA, assim como a determinação de outras eventuais exigências legais adicionais no âmbito de suas competências territoriais (BRASIL, I98I).

O processo de Licenciamento Ambiental para instalação de minerodutos decorre, inicialmente, da obtenção da Licença Prévia, quando são realizadas negociações e arrendamentos das terras que serão ocupadas pelo traçado das estruturas e faixa de servidão de $30 \mathrm{~m}$. Posteriormente, a empresa precisa obter a Licença de Instalação para iniciar as obras de implementação e, então, é necessário que o empreendimento obtenha a Licença de Operação para dar início às atividades (PASINI; OLIVEIRA; FONSECA, 20I3).

Para a efetivação do licenciamento das atividades de minerodutos, também deve ser realizada a análise da concessão de uso das águas através das outorgas. No caso de cursos d'água federais, a outorga é realizada pela ANA, e, no caso dos estaduais, o processo fica a cargo dos respectivos órgãos ambientais. Em Minas Gerais as outorgas são deliberadas pelo IGAM (MINAS GERAIS, I999). Atendendo aos princípios da Política Nacional de Recursos Hídricos (BRASIL, I997), a cobrança pelo uso da água é definida de acordo com o tipo de captação (superfície ou subterrânea), vazão, finalidade, tipo de efluentes e tratamento, aproveitamentos potenciais em outros setores, dentre outros aspectos definidos pelo comitê gestor da respectiva bacia hidrográfica. 
Outros dois aspectos legais importantes no planejamento dos minerodutos no Brasil são relativos à Compensação Financeira pela Exploração de Recursos Minerais (CFEM) e ao papel da Agência Nacional de Transportes Terrestres. A CFEM, criada pela Lei $\mathrm{N}^{\mathrm{o}}$ 7.990, de 28 de dezembro de I980, é uma taxa de arrecadação municipal advinda do aproveitamento econômico gerado pela exploração mineral. Segundo o Decreto $n^{\circ}$ 9.407, de I2 de junho de 20I8, uma parcela da CFEM deve ser direcionada aos municípios não produtores de minério, mas que são afetados por empreendimentos como minerodutos. Sobre esse aspecto, a ANM (20I8) pondera que muitos municípios acabam priorizando o retorno financeiro promovido pela CFEM em detrimento dos impactos das estruturas (ANM, 20I8). A ANTT foi criada pela Lei $\mathrm{n}^{\mathrm{o}} \mathrm{I0.233}$, de 05 de junho de 200I, tendo como função regulamentar, cadastrar e integrar informações sobre os modais de transporte brasileiros, disponibilizando dados sobre as dutovias em meio virtual e de livre acesso ao público. Essa base é relevante para o processo de licenciamento dos minerodutos, pois integra diferentes tipos de dados e possibilita uma melhor compreensão das dimensões ambientais e sociais dos territórios envolvidos.

O estado de Minas Gerais passou por recente dinamismo em seu aparato legal relativo à estruturação e operação de minerodutos, fato incentivado pelo contexto de baixos índices pluviométricos entre os anos de 2013 e 20I5. Esse cenário acarretou uma sensível redução dos níveis dos reservatórios e os órgãos gestores, com destaque para a Companhia de Saneamento de Minas Gerais - COPASA, não foram capazes de atender as demandas hídricas da população em vários municípios, gerando uma crise de abastecimento na maior parte do estado. Tal quadro foi definido pelos órgãos gestores como uma suposta "crise hídrica", ainda que as causas sejam naturais e apresentem caráter cíclico. A redução da disponibilidade hídrica veio na contramão dos argumentos tradicionais, por parte do Estado e do setor minerário, que defendem os minerodutos como melhor opção de modal para escoamento do minério com menores implicações ambientais. Essa questão foi pauta de discussão acirrada entre políticos, técnicos e ambientalistas na Assembleia Legislativa de Minas Gerais. Os debates e questionamentos se concentraram, principalmente, nos volumes de água outorgados para os minerodutos com o complicador das diversas esferas legislativas envolvidas no processo de licenciamento. 
No contexto mencionado, dois Projetos de Lei (PL) foram apresentados na ALMG: o PL I22I/20I5 e o PL 263/20I5 (ALMG, 20I5). O primeiro defende que haja a implementação de um sistema de tratamento da água utilizada pelos minerodutos, para que a mesma retorne, com qualidade, ao seu local de origem por meio de bombeamentos, como mostra o artigo primeiro: "Ficam obrigadas todas as mineradoras do Estado que utilizem o sistema de minerodutos a retornar toda a água utilizada no sistema de mineroduto ao local de que foi retirada, devidamente tratada" (ALMG, 20I5). Essa proposta buscou minimizar os impactos da extração de grandes volumes de água de cabeceiras de drenagem de mananciais mineiros, os quais, após utilizados exclusivamente para transporte de minério, acabariam sendo “perdidos” no oceano. Após poucos dias de tramitação, o PL I221/20I5 foi anexado ao PL 263/20I5 que, mais maleável, defendia que apenas metade do volume da água captada deveria ser tratada e devolvida à bacia de origem, em Minas Gerais. Passados oito meses de sua criação, o PL 263/20I5 foi retirado de pauta, o que pôde indicar a pressão e força política do setor minerário, sobrepondo, até mesmo, os interesses do próprio governo do estado relativos ao aumento da disponibilidade hídrica (ALMG, 20I5).

Entretanto, no dia 28 de maio de 20I9, O PL I.22I/I5 voltou à pauta na Comissão de Constituição e Justiça da ALMG por meio do parecer do deputado Charles Santos (PRB). O deputado Guilherme da Cunha (Partido Novo) pediu adiamento para nova análise, alegando que seus termos contrariam a legislação referente às águas, afirmando que tais termos são de responsabilidade da União (BRASIL, I98I). Em 04/06/2019, o parecer teve legalidade e seguiu para análise na Comissão de Minas e Energia (ALMG, 2019).

\section{Contexto territorial dos minerodutos em Minas Gerais}

Atualmente, três linhas de minerodutos ativos se originam em Minas Gerais, transportando polpa de minério de ferro e de fosfato. Além desses, há duas linhas previstas e uma que foi proposta recentemente e cancelada, conforme observa-se na Figura I. 
JÚNIOR, A. P. M.; CARVALHO, R. P. B.; FACURY, D. M.; CAMILO, G. A.; RAMANERY,G.S.

MINERODUTOS E IMPLICAÇÕES SOCIOAMBIENTAIS: PANORAMA LEGAL E REFLEXÕES PARA O CENÁRIO DE MINAS GERAIS

Figura 1 -Minerodutos em Minas Gerais

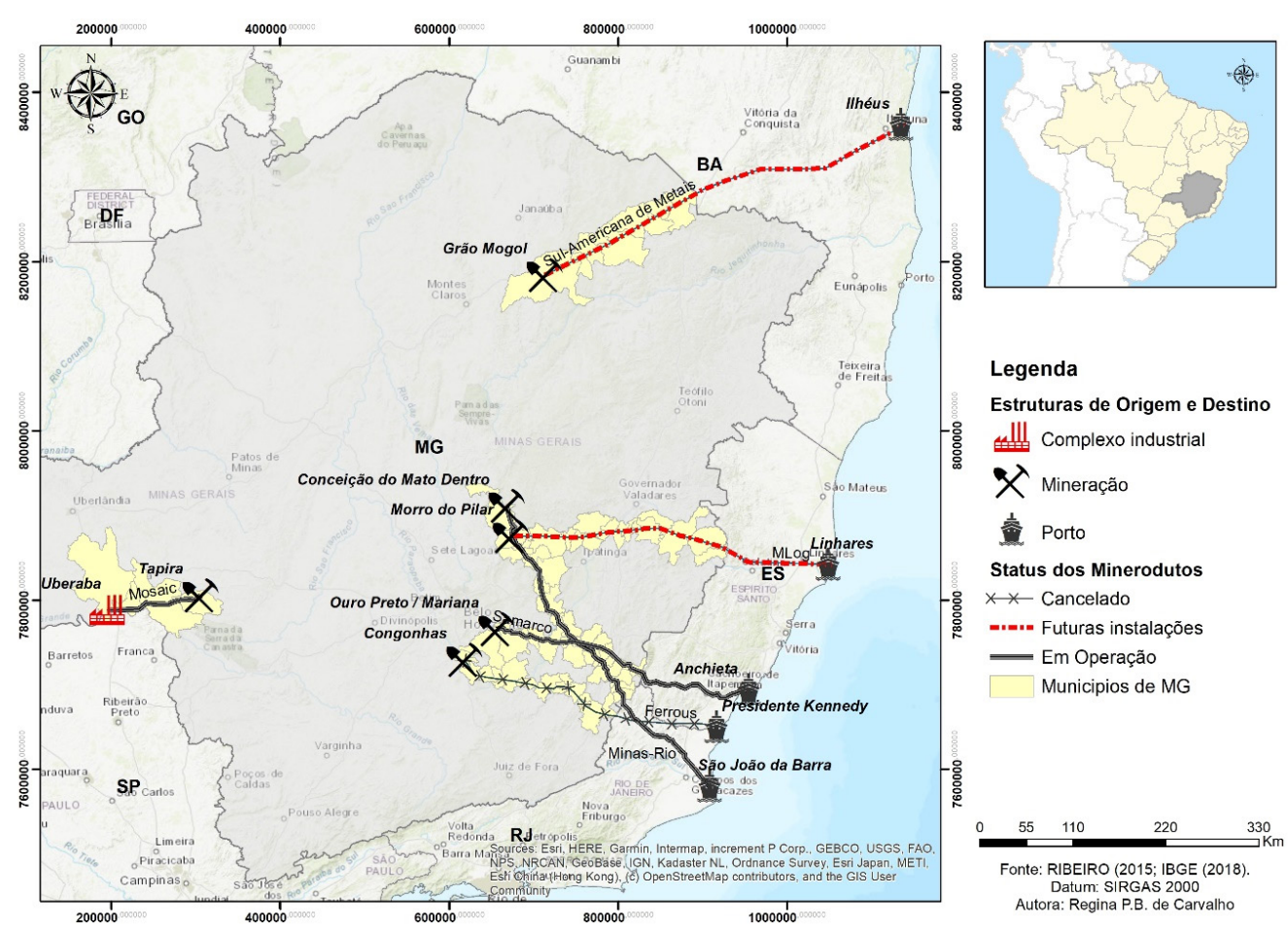

Dentre os três minerodutos ativos, a linha menos extensa é a que liga o Complexo

2 Empresa de capital aberto com sede nos

Estados Unidos da América, especializada na produção de fertilizantes. Possui minas em diversos estados do Brasil. É a maior mineradora do combinado fosfato-potássio do mundo

(MOSAIC, 2019). de Mineração de Tapira (MG) ao Complexo Industrial de Uberaba (MG), ambos construídos em I978 pela empresa estatal Fosfértil, que viria a ser privatizada em I992. A Fosfertil foi comprada pela Vale Fertilizantes em 20I0, e em 2017 o empreendimento foi novamente vendido, dessa vez para a mineradora norte-americana Mosaic ${ }^{2}$ (VALE..., 20I8). A linha conta com tubulação única, com cerca de I20 km de extensão, sendo a maior parte enterrada e atravessando cinco municípios do Triângulo Mineiro: Tapira, Conquista, Delta, Sacramento e Uberaba (ANM, 20I9). Esse duto transporta polpa de minério de fosfato com 6I\% de sólidos e 39\% de água (SANTOS et al., 2002). A quantidade de minério transportado nos últimos anos pode ser observada na Tabela I. 
Tabela 1- Mineroduto (rocha fosfática) no Complexo de Mineração Tapira (2010-2017)

\begin{tabular}{lllllllll}
\hline Ano & 2010 & 2011 & 2012 & 2013 & 2014 & 2015 & 2016 & 2017 \\
\hline $\begin{array}{l}\text { Milhões de } \\
\text { Toneladas }\end{array}$ & 2,07 & 2,01 & 2,07 & 1,87 & 2,01 & 1,97 & 1,63 & - \\
\hline
\end{tabular}

Fonte: MTPA, 2018.

A linha esteve inutilizada entre $20 \mathrm{I7}$ e grande parte de $20 \mathrm{I9}$ por conta de irregularidades encontradas na barragem de rejeitos BLI, em Tapira. Isso causou diversos transtornos ao município, principalmente pela queda de arrecadação gerada pela mineração. Em setembro de 2019 a empresa declarou que as operações retornariam integralmente devido à Declaração de Condição de Estabilidade das barragens de rejeito, concedida pela ANM (MOSAIC..., 20I9). Esse mineroduto apresenta a peculiaridade de ser o único, no contexto de Minas Gerais, a escoar o minério para o interior do país, especificamente para o Complexo Industrial de Uberaba. Todos os demais escoam para portos no litoral. O município de Tapira situa-se na bacia do rio Paranaíba, da qual é retirada a água utilizada no mineroduto, enquanto Uberaba se localiza na bacia do rio Grande, onde a água do mineroduto é despejada. Esse cenário caracteriza uma transposição de águas interbacias, que se configura como uma das pautas de discussão do PL I.22I/I5.

As outras duas linhas de minerodutos construídas transportam minério de ferro. Uma pertence à empresa Samarco 3 e conta com três dutos paralelos e próximos, construídos em períodos distintos, com origem entre os municípios de Mariana e Ouro Preto e que seguem para o litoral capixaba (SAMARCO, 20I5). A outra linha pertence à Anglo American 4, e possui apenas um duto que se inicia em Conceição do Mato Dentro e segue em direção ao litoral fluminense - vide Figura I.

O processo de mineração do minério de ferro, resumidamente, passa pela extração, beneficiamento, transporte, produção de pelotas ou filtragem e exportação. Minas Gerais é o primeiro estado em produção de minério de ferro do país, o que se dá, principalmente, pela grande quantidade de jazidas no Quadrilátero Ferrífero ${ }^{5}$, as quais são exploradas por grandes empresas como Vale e Samarco (DNPM, 20I8). Essa faz uso de três minerodutos paralelos (Samarco I, 2 e 3) para o escoamento de sua produção.

A mineração no Complexo do Germano, na divisa entre Mariana e Ouro Preto, teve a lavra concedida em I967 para a Samitri - S.A. Mineração Trindade, mineradora de

3 Empresa de capital fechado formada por jointventure entre a Vale S.A. e a BHP Billiton (SAMARCO, 2015). É responsável pela Barragem de Fundão que se rompeu em Mariana em 2015.

4 Empresa de capital aberto com sede em Londres que produz carvão, cobre, ferro, platina, níquel e diamante. Em 2018, o fluxo global de caixa livre foi de cerca de US\$3,2 Bi (ANGLO AMERICAN, 2019).

5 O Quadrilátero Ferrífero é uma unidade geológica localizada ao sul de Belo

Horizonte e que abrange a bacia do Alto Rio das Velhas (afluente do São Francisco). O Quadrilátero vem sendo intensamente explorado durante os últimos três séculos para a retirada de ouro e ferro. As grandes jazidas de ferro ocorrem associadas a rochas itabiríticas, com diversas minas ainda ativas (CAXITO; DIAS, 2018). O Quadrilátero compreende, também, importantes áreas de recarga dos principais mananciais que abastecem a capital mineira, gerando constantes tensões ambientais entre a atividade minerária e o setor de abastecimento de água. 
Luxemburgo (ANM, 2019). Em I975, a Samitri e a Marcona Corporation iniciaram as obras do chamado "Projeto Samarco", que continha a extração e transporte do minério via mineroduto. Em 1977, fundou-se a Samarco, em uma parceria das duas empresas. Nesse mesmo ano teve início a lavra e transporte de minério de ferro pelo mineroduto (AMPLO, 20I7). No ano 2000, a Samitri e a Samarco foram compradas pela VALE, em um joint-venture entre a empresa brasileira e a australiana BHP Billiton (VALE, 2000). A construção dos minerodutos Samarco 2 e 3 ocorreu já no século XXI, e foi condicionada pela variação do preço do minério de ferro no mercado internacional, principalmente a partir de 2004 (Figura 2). Esse foi o mesmo cenário da construção do mineroduto da Anglo American. Portanto, a construção de minerodutos no Brasil, no século XXI, esteve fortemente relacionada à cotação internacional do minério de ferro.

Figura 2 -Variação do Preço do Minério de Ferro (1989-2019)

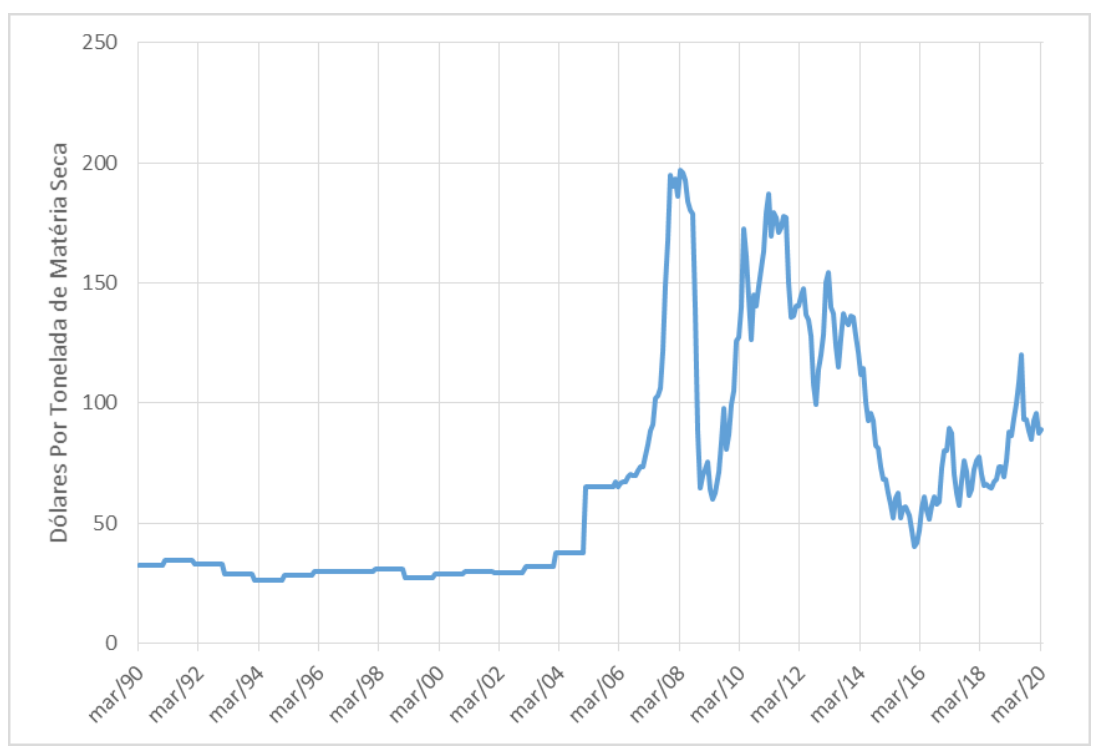

Fonte: IndexMundi, 2019.

Os minerodutos 2 e 3 da Samarco foram concluídos em 2008 e 20I4, respectivamente. Assim como o Samarco I, percorrem $400 \mathrm{~km}$ de extensão territorial ao longo de 25 municípios de Minas Gerais e Espírito Santo. A capacidade de transporte total dos três minerodutos é de 36 milhões de toneladas de minério de ferro por ano, o qual é transportado em forma de polpa com cerca de 70\% de sólidos e 30\% de água (SAMPAIO; BRANDÃO, 2002). A polpa passa pelo processo de pelotização na Unida- 
de Ubu, no município de Anchieta (ES). Segundo a empresa, a água utilizada provém do beneficiamento do minério, sendo, posteriormente, reaproveitada nos processos de pelotização (SAMARCO, 20I5). As operações da Samarco em Mariana foram paralisadas após o rompimento da Barragem de Fundão (novembro de 20I5) e somente em outubro de 20I9 a empresa obteve a licença para voltar a operar (CANOFRE, 20I9).

$\mathrm{O}$ mais recente mineroduto construído em Minas Gerais pertence à Anglo American e faz parte do Projeto Minas-Rio (ANGLO AMERICAN, 20I5). Apresenta um único duto com $529 \mathrm{~km}$ de extensão que atravessa 33 municípios, partindo de Conceição do Mato Dentro (MG) até o Porto de Açu, em São João da Barra (RJ), com uma duração do percurso total de quatro dias. Em março de 2018 ocorreram dois vazamentos no mineroduto Minas-Rio, no município de Santo Antônio do Grama (MG), despejando cerca de 470 toneladas de polpa de minério de ferro no ribeirão Santo Antônio do Grama, curso d'água tributário do Rio Santo Antônio, importante afluente do Rio Doce (IPT, 20I8). A Tabela 2 mostra a evolução temporal do transporte de minério de ferro via minerodutos pela Samarco e pela Anglo American entre os anos de 2010 e 2017. Pode-se verificar que as quantidades da primeira são bem mais elevadas em relação à segunda.

Tabela 2- Transporte de minério de ferro (milhões de ton.) via minerodutos pelas empresas Samarco e Anglo American

\begin{tabular}{llllllllll}
\hline Mineroprodutos & Empresa & $\mathbf{2 0 1 0}$ & $\mathbf{2 0 1 1}$ & $\mathbf{2 0 1 2}$ & $\mathbf{2 0 1 3}$ & $\mathbf{2 0 1 4}$ & $\mathbf{2 0 1 5}$ & $\mathbf{2 0 1 6}$ & $\mathbf{2 0 1 7}$ \\
\hline $\begin{array}{l}\text { Mariana (MG) } \\
\text { - Ponta do Ubu } \\
\text { (ES) }\end{array}$ & Samarco & 23,33 & 22,44 & 22,07 & 21,74 & 26,29 & 25,36 & 0,00 & - \\
\hline $\begin{array}{l}\text { Conceição do } \\
\text { Mato Dentro } \\
\text { (MG) - São João } \\
\text { da Barra (RJ) }\end{array}$ & Amplo & 0,00 & 0,00 & 0,00 & 0,00 & 0,70 & 9,20 & 16,10 & 16,80 \\
\hline
\end{tabular}

Fonte: MTPA, 2018.

Outros minerodutos para transporte de minério de ferro foram cogitados ou ainda estão em licenciamento em Minas Gerais (vide Figura I). O duto da empresa Ferrous Resources, que ligaria a mina Viga, em Congonhas (MG), ao porto de Presidente Kennedy (ES), foi cancelado em 2016 devido a pressões populares e à queda do preço do minério. A proposta do modal dutoviário foi substituída pela alternativa ferroviária (PIZARRO, 20I6). Dois outros minerodutos ainda estão sendo discutidos. O da 
JÚNIOR, A. P. M.; CarValho, R. P. B.; Facury, D. M.; CAMILO, G. A.; RAMANery,G.S.

MINERODUTOS E IMPLICAÇÕES SOCIOAMBIENTAIS: PANORAMA LEGAL E REFLEXÕES PARA O CENÁRIO DE MINAS GERAIS

6 Empresa brasileira fundada em 2006 e controlada pela Honbridge Holdings Ltd. Essa companhia chinesa não tem outros empreendimentos no Brasil, sendo o de Grão Mogol a sua principal aposta (SAM, 2019).

7 A MLog é uma empresa de capital aberto especializada em logística e navegação. Recentemente, adquiriu os direitos de exploração de ferro em Morro do Pilar, a ser feita por sua subsidiária MOPI (MLOG, 2019). empresa Sul Americana de Metais ${ }^{6}$ ligaria Grão Mogol (MG) à Ilhéus (BA) e teve o licenciamento rejeitado pelo IBAMA em 20I6. Porém, a empresa voltou a licenciar o empreendimento, que já obteve outorga para uso da água e busca a Licença Prévia. O mineroduto da empresa MLog ${ }^{7}$ (antiga Manabi) tem sido proposto e teria origem em Morro do Pilar (MG), município limítrofe a Conceição do Mato Dentro, onde se origina também o mineroduto da Anglo American. O novo empreendimento teria como destino o porto de Linhares (ES), mas a sua construção está atrelada ao processo de licenciamento da mina, que já obteve a Licença Prévia e agora visa a Licença de Instalação junto à SEMAD/MG (SUPRAM JEQUITINHONHA, 2OI8).

Impactos e conflitos do processo de licenciamento dos minerodutos em Minas Gerais

Os impactos causados por minerodutos podem limitar usos da terra e da água de diferentes atores sociais, criando situações de conflitos associadas às três etapas do processo de licenciamento: (I) na licença prévia, durante a negociação para desapropriação das terras; (2) na licença de instalação, quando as obras são implantadas; e (3) na licença de operação, fase em que a estrutura entra em atividade. Neste tópico é apresentado um panorama dos impactos reais/potenciais e tensões associadas a essas três etapas considerando minerodutos já em funcionamento ou licenciamento. Essas implicações envolvem, particularmente, certas incompatibilidades de interesses referentes aos usos da água. Vale apontar que as situações relacionadas aos minerodutos da Ferrous Resources, MLog e Sul Americana de Metais tratam, principalmente, do licenciamento, da desapropriação e de negociações pela terra, tendo em vista que as obras não foram implementadas. As informações sobre essas empresas citadas nos tópicos "instalação" e "operação" provêm dos EIA/RIMAs e de suas respectivas outorgas pelo uso da água. 


\section{Etapa de desapropriação e negociações pela terra}

Os trâmites legais para obtenção das licenças ambientais dos minerodutos geralmente são feitos por empresas de logística que realizam a operação/gestão das estruturas, como é o caso da MMX para o mineroduto da Anglo American (BRANDT, 2006). Dessa forma, o complexo minerário se estende em duas ou três frentes de licenciamento: a primeira para a área da mina (feito pela empresa de mineração), a segunda para o mineroduto (feito pela empresa de logística), e uma possível terceira, para as estruturas atreladas ao local de escoamento e destino do minério como as estruturas portuárias, construídas no litoral brasileiro.

Como já mencionado, o processo de regularização de minerodutos em Minas Gerais envolve mais de um órgão licenciador por conta da extensão dos projetos. Por isso, é comum que os minerodutos sejam licenciados de forma autônoma em relação às minas (licenciadas no âmbito estadual), e aos portos (licenciados pela federação ou estados litorâneos). Essa situação dificulta a análise integrada das alterações que podem ser causadas pelo complexo mina-mineroduto-portos, desconsiderando impactos cumulativos. Além disso, há uma distribuição do licenciamento de estruturas complementares ao complexo, que envolve vários órgãos públicos e empresas, fato que pode resultar em brechas legais que atenuam a relevância de impactos e a proposição de medidas de mitigação e compensação atreladas às atividades, caso os órgãos não alinhem suas análises.

Os minerodutos, mesmo sendo estruturas majoritariamente subterrâneas, exigem uma área de servidão superficial para possíveis reparos com, geralmente, mais de 30 metros de largura (PASINI; OLIVEIRA; FONSECA, 20I3). Para isso, a aquisição dessas áreas pelas empresas necessita ser negociada com todos os proprietários de terras envolvidas. Em Minas Gerais, há relatos de diversos casos de abusos de empresas e diferenças na condução dos diálogos de acordo com o nível de escolaridade e de conhecimento de proprietários durante a negociação de terras. Isso ocorreu, por exemplo, em Viçosa-MG, município que seria atravessado pelo mineroduto da Ferrous Resources (SOUSA; OLIVEIRA, 20I5). A empresa chegou a negociar terras e realizar audiências públicas durante o processo de elaboração do EIA/RIMA, consultando a população. Porém, a instalação do mineroduto não foi concluída devido a pressões populares e quedas no preço do minério de ferro naquele período (PIZARRO, 20I6). Em outro 
JÚNIOR, A. P. M.; CarValho, R. P. B.; Facury, D. M.; CAMILO, G. A.; RAMANery,G.S.

MINERODUTOS E IMPLICAÇÕES SOCIOAMBIENTAIS: PANORAMA LEGAL E REFLEXÕES PARA O CENÁRIO DE MINAS GERAIS

caso, Ribeiro (20I7) identificou diversas ações da Manabi (atual MLog) para impedir uma maior articulação entre proprietários quanto à valorização de terras no município de Ferros (MG). Dentre elas, o autor cita a prática de se negociar as terras antes de concluir o processo de licenciamento. Tal fato aumenta a pressão política pela rápida aprovação da atividade no órgão ambiental responsável (que geralmente é o IBAMA), fazendo com que, muitas vezes, não haja tempo hábil para uma análise completa e cautelosa a respeito dos impactos e de seus desdobramentos, assim como para o levantamento de medidas de prevenção ou mitigação.

\section{Etapa de instalação das estruturas}

Uma vez adquirida a Licença de Instalação, iniciam-se as obras de construção, fase em que os impactos socioambientais são sentidos de forma mais significativa. Dentre eles, destacam-se os que alteram a morfodinâmica do meio natural (relevo, drenagem, solos, biota) e do meio social, com a modificação de vias, limitações de uso das terras e dificuldades de acesso a serviços básicos pela população devido às obras (RIBEIRO, 20I7).

A implantação de um mineroduto requer a supressão da cobertura vegetal e o revolvimento do solo em sua área de servidão, deixando-o exposto e suscetível aos processos de erosão acelerada. A remoção de partículas pelos fluxos pluviais nas encostas tende a resultar em uma maior carga sedimentar para os cursos d'água, comprometendo a dinâmica hídrica e ecológica. Por consequência, aumenta-se a turbidez das águas, com gradual redução de sua qualidade e aumento dos riscos de assoreamento de cursos d'água (BRANDT, 2006). A supressão da vegetação também reverbera na fauna local. Segundo o RIMA do mineroduto Minas-Rio (BRANDT, 2006), o desmatamento ao longo do traçado do mineroduto descaracterizou o habitat de algumas espécies de mastofauna, herpetofauna e fauna aquática, comprometendo a biodiversidade, a permanência e a reprodução por extensas áreas (BRANDT, 2006). Em alguns casos, os dutos impactam diretamente Áreas de Preservação Permanente (APPs), atravessando margens fluviais e zonas de entorno de nascentes, causando instabilidades a processos erosivos e comprometendo as funções ecológicas amparadas por lei. Na alocação de um mineroduto, também podem ocorrer impactos relativos à intensa movimentação de maquinário, como possíveis vazamentos de óleo dos veículos, que podem degradar ainda mais os solos e os sistemas fluviais. 
Em situações de travessias de cursos d'água, o mencionado RIMA do mineroduto Minas-Rio sugere e especifica a aplicação de duas técnicas para proceder à instalação do duto: escavação do leito fluvial e instalação de tubulação transversalmente ao curso d'água, posteriormente recoberta com o material retirado; técnica do "cavalote", na qual o duto é atravessado no substrato sob o curso d'água, sem alterar as características do leito, implicando em maiores custos (BRANDT, 2006). A escolha depende das dimensões e características do curso d’água. Porém, ao observarmos a travessia do mineroduto Minas-Rio, construída no Córrego do Galo (bacia do rio Paraíba do Sul), verifica-se que nenhuma das duas técnicas propostas foi aplicada. Ao examinarmos as imagens dos anos 20II e 20I9, verifica-se que o duto sobrepôs o leito fluvial, causando grandes alterações na sinuosidade do canal (Figura 3). Impactos como esse podem modificar sensivelmente o comportamento do canal e as características de vales e planícies adjacentes, reduzindo a capacidade de retenção de água entre os trechos fluviais e, portanto, a abrangência das inundações dos terrenos. Por consequência, a menor acumulação de água induz à perda de áreas úmidas e da biota que se estabelece por meio de tais condições físicas.

Figura 3 -Morfologia fluvial do Córrego do Galo, em Pedra Dourada (MG), antes (2011) e após (2019) as obras do mineroduto Minas-Rio

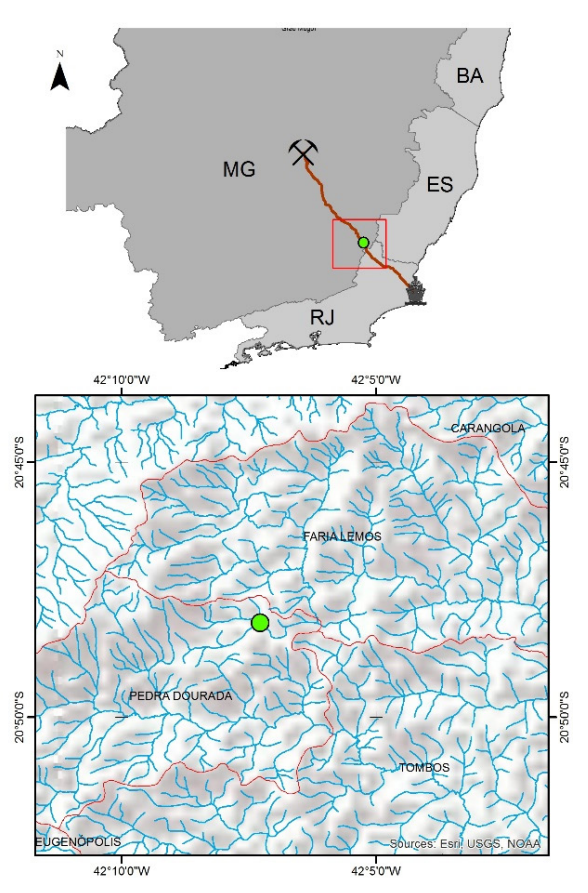

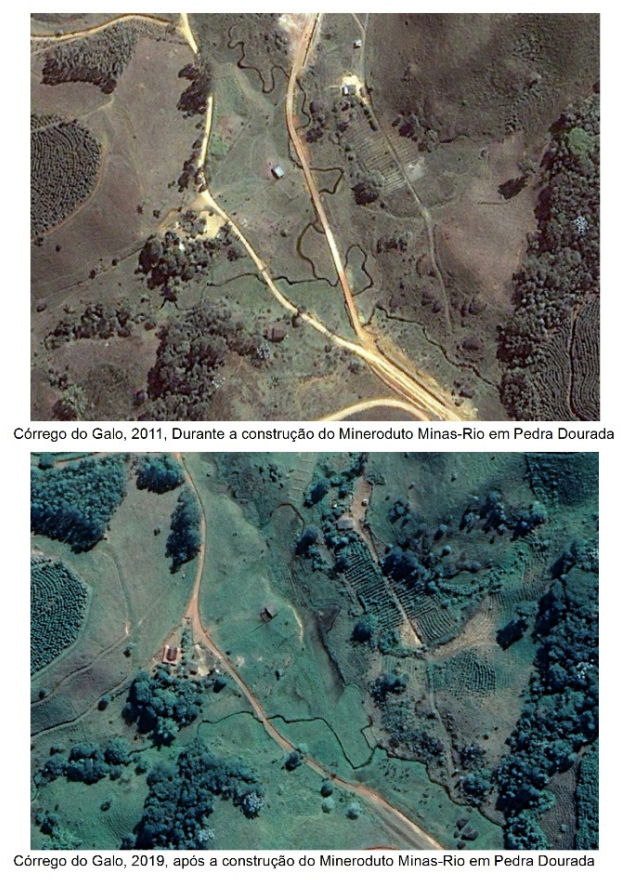

Fonte: Adaptado de SISEMA (2020); Google Earth Pro (2011; 2019). 
JÚNIOR, A. P. M.; CarValho, R. P. B.; Facury, D. M.; CAMILO, G. A.; RAMANery,G.S.

MINERODUTOS E IMPLICAÇÕES SOCIOAMBIENTAIS: PANORAMA LEGAL E REFLEXÕES PARA O CENÁRIO DE MINAS GERAIS

Em termos sociais, as comunidades no entorno de minerodutos são as primeiras a sentir seus efeitos negativos, seja por modificações em sua rotina, interferência na alocação de recursos para as comunidades e/ou limitação dos usos da terra a partir da efetivação de sua faixa de servidão. Alguns exemplos ilustram as tensões geradas na população, direta e indiretamente atingida, como o potencial caso da construção do mineroduto da MLog, Morro do Pilar/Linhares. De acordo com o parecer do empreendimento, houve negligência na especificação das dimensões de recobrimento da faixa de servidão, principalmente em relação às áreas adicionais, chamadas nas etapas de licenciamento de Áreas de Material Excedente (ADMEs). A localização precisa destas áreas não foi especificada no projeto, sendo realizada apenas uma perspectiva generalizada, fazendo com que os moradores do local não tivessem a devida compreensão sobre os impactos que seriam causados em suas propriedades (GESTA, 20I4). Outro exemplo é o caso do mineroduto da Ferrous Resources, que foi planejado para ocupar áreas onde se situam cerca de 30 nascentes na bacia do ribeirão São Bartolomeu, região leste de Minas Gerais, o qual é responsável pelo fornecimento de água para 50\% da população da cidade de Viçosa (PASINI; OLIVEIRA; FONSECA, 20I3). Caso tivesse sido implantado, o município possivelmente teria que realizar a captação de água para abastecimento público em outros mananciais mais distantes.

A atração populacional associada à geração de empregos também pode se refletir em impacto durante a instalação dos minerodutos. Apesar do apelo positivo para os contratados, o processo pode ser sentido de forma negativa pelos municípios, já que podem ocorrer fluxos migratórios desproporcionais à capacidade de atendimento em termos de recursos, serviços e infraestrutura básica. Esse contexto foi previsto no estudo ambiental do projeto do mineroduto da MLog em Morro do Pilar, que aponta que o aumento do contingente populacional tende a dificultar o acesso aos serviços de saúde e educação, além do perigo de aumento da violência urbana. Ademais, não há previsão de que a população residente antes da obra seja beneficiada pelos empregos, ou seja, a cidade pode receber um importante fluxo migratório que pressione a infraestrutura municipal (GESTA, 20I4). 


\section{Etapa de operação dos minerodutos}

Após a instalação do empreendimento e a concessão da Licença de Operação (LO), os minerodutos iniciam suas atividades e começam a captar grandes volumes de água dos mananciais para o transporte do minério. O uso depende da outorga por parte do IGAM, no caso de águas mineiras, ou da ANA, no caso de águas federais (BRASIL, I997; MINAS GERAIS, I999). As captações destinadas aos minerodutos podem impactar significativamente a disponibilidade hídrica local e/ou regional. A polpa na qual o minério é transportado pode possuir até 30\% de água (SAMPAIO; BRANDÃO, 2002). A tubulação do mineroduto Minas-Rio tem capacidade de transportar mais de 25 milhões de toneladas de minério de ferro por ano, com uma vazão de $2.105 \mathrm{~m}^{3} / \mathrm{h}$ de polpa, que resulta no uso de 631,5 $\mathrm{m}^{3}$ de água/hora ou $\mathrm{I} 5 \mathrm{I} 56 \mathrm{~m}^{3}$ de água/dia (BRANDT, 2006). Esse valor seria suficiente para atender à média brasileira de consumo diário de água para cerca de I40 mil pessoas ${ }^{8}$ (IBGE, 20I5). Considerando a média de água distribuída para Conceição do Mato Dentro, município de origem do mineroduto, no ano de 20I5, a quantidade de água utilizada pelo mineroduto seria suficiente para abastecer 72 mil cidadãos, contando com as perdas de água na distribuição e tratamento (SNIS, 20I9) 9 . Além da água utilizada para o transporte do minério, as pressões também decorrem do aumento das demandas hídricas municipais em termos de abastecimento público, já que há um aumento populacional associado aos trabalhadores das obras. Paralelamente, há pressões relacionadas ao aumento dos efluentes gerados, ou seja, pressões no sistema de tratamento de esgotos para que tais efluentes não sejam despejados in natura nos corpos d'água.

Estudos ambientais relativos ao processo de licenciamento do mineroduto da Sul Americana de Metais, em Grão-Mogol, indicam que a empresa já obteve a outorga da ANA para captação de água do rio Jequitinhonha, na Usina Hidrelétrica de Irapé (ANA, 20I2; SAM, 20I9). Essa se refere a uma vazão média de quase $6000 \mathrm{~m}^{3} / \mathrm{h}$ durante 24 horas por dia, sendo a água destinada a todo o complexo minerário. O projeto conta ainda com a construção de uma barragem de água no rio Vacaria (afluente do Jequitinhonha), em Grão Mogol, que, junto à outorga da esfera estadual, destina mais $6000 \mathrm{~m}^{3} / \mathrm{h}$ para a mineradora (BRANDT, 20I9). Esse grande volume de água poderia abastecer quase três milhões de cidadãos com o padrão anual de consumo do morador médio de Grão-Mogol (SNIS, 20I9) ${ }^{\text {Io }}$. As mesorregiões mineiras do Vale do

8 Esse valor é hipotético. A média nacional de consumo de água é de 1.081/dia, mas as médias podem esconder diferenças importantes em termos espaciais e podem camuflar as perdas nos sistemas de distribuição. No entanto, a comparação é válida para dar uma ideia da quantidade de água utilizada no mineroduto em relação ao consumo médio de um brasileiro.

9 Informações referentes ao ano de 2015 para a produção de água pela COPASA e população atendida no referido município. A taxa produção/população atendida obtida foi de 210 litros/habitante/dia.

10 Informações referentes ao ano de 2017 para o consumo de água e população atendida no município de Grão Mogol. A taxa consumo/população atendida é de 98 litros/ habitante/dia. O uso de água da mineradora foi calculado pelo produto da vazão média $\left(12.000 \mathrm{~m}^{3} / \mathrm{h}\right)$ pelo regime de operação em horas discriminado na outorga da ANA (24 horas). morador médio de Grão-Mogol (SNIS, 201g) . As mesorregiōes mineiras do Vale do 
Jequitinhonha e Mucuri, Norte e Noroeste de Minas têm, em conjunto, pouco mais de 2,8 milhões de habitantes e convivem com constante situação de escassez hídrica (MINAS GERAIS, 20I9).

Os minerodutos da Samarco, da Anglo American e do projeto da MLog se localizam na bacia do rio Doce, que há séculos vem sendo impactada pelo histórico de uso da terra, inclusive por atividades minerárias e desastres decorrentes, como o caso do rompimento da Barragem de Fundão em 20I5. Mesmo antes desse desastre, a bacia era apontada como uma das mais impactadas pela erosão acelerada e turbidez elevada das águas fluviais no estado (ECOPLAN; LUME, 20IO). O Quadrilátero Ferrífero, que tem a sua borda leste inserida na bacia do Alto Rio Doce, ainda é uma área de forte interesse minerário, o que gera um quadro potencial de constante atração para construção de novos minerodutos e consumo de água. No entanto, adjacente ao sistema rio Doce, a bacia do Alto Rio das Velhas atravessa o Quadrilátero Ferrífero e concentra a maior parte das atividades minerais do estado. Concomitantemente, a bacia concentra importantes mananciais responsáveis pelo abastecimento de água de quase metade da população da Região Metropolitana de Belo Horizonte. A sobreposição de interesses de uso da água nessa região configura diversas situações de tensões entre o setor minerário e a sociedade civil (RIBEIRO et al., 20I8). Fato é que a quantidade de minério transportado varia de acordo com os preços no mercado internacional, com os estoques nos portos e com situações políticas ou eventos de rompimentos, fazendo com que a água utilizada não leve em consideração a conjuntura ambiental na bacia de origem, como situações emergenciais relacionadas à escassez e à segurança hídrica de um grande contingente populacional.

\section{Pontos de reflexão}

Em realidades de economia fortemente atreladas ao setor da mineração, os minerodutos tornam-se modais de transporte bastante atrativos para o escoamento da produção por sua praticidade, rapidez e custos. Contudo, há implicações socioambientais que se manifestam em tensões e conflitos de interesses, de caráter intra e interterritoriais. Os conflitos são muitas vezes desencadeados pela insegurança jurídica gerada pela sobreposição de regimentos legais e ineficiência burocrática entre as entidades 
federativas para a normatização dos minerodutos e outorga de uso de recursos hídricos. Os trâmites políticos e econômicos, a morosidade dos processos, a constatação por parte da população de impactos muitas vezes irreversíveis nos sistemas fluviais e a verificação de negociações abusivas entre as partes interessadas no funcionamento da atividade acirram ainda mais as discussões entre os diferentes usuários (públicos, privados e entidades civis). Esse conjunto de fatos comprova a prerrogativa inicial de que a instalação e operação de minerodutos pode potencializar ameaças de desastres socioambientais relativos à escassez hídrica.

Tratando-se de interesses distintos entre o setor de abastecimento público e as mineradoras, não há soluções fáceis. A elevada demanda hídrica, um dos principais pontos de questionamentos e tensões derivadas dos minerodutos, ilustra a necessidade de ponderação nos processos de licenciamento. É importante levar em conta se os benefícios econômicos são compensadores à luz dos impactos nos mananciais, no ambiente como um todo e principalmente no setor de abastecimento público. Por um lado, a água é um elemento vital e essencial para as atividades humanas, sendo um direito legal que deve ser atendido pelos municípios (BRASIL, I997). Por outro, a mineração garante recursos financeiros e torna-se, comumente, a maior fonte de divisas para os municípios mineradores. Nesse contexto, há choques de interesses que perpassam diferentes setores, inclusive dentro do próprio âmbito político, e que podem acabar privilegiando as dimensões mais fortes do capital em detrimento do interesse público.

Algumas vezes os impactos podem não ser sentidos de imediato pelos usuários das águas de mananciais captados para os minerodutos. No entanto, quando esses impactos são avaliados sob o aspecto temporal e magnitude de sua ação no sistema ambiental, aliados ao gradual aumento da demanda por água e a eventuais fatores naturais (por exemplo, a variação e distribuição irregular da pluviosidade ao longo dos meses e anos), constata-se que os mesmos podem ser responsáveis por reduções abruptas na oferta e qualidade das águas e por intensificação de períodos de seca. Assim, os minerodutos se mostram como indutores de situações de desastres relacionadas à indisponibilidade hídrica em uma bacia.

Portanto, o aumento dos riscos de geração de quadros de insegurança hídrica em um estado com fortes desigualdades territoriais em termos de acesso a água deve ser considerado na aprovação de propostas de minerodutos. Os Projetos de Lei $\mathrm{N}^{\circ}$ I22I/20I5 e $\mathrm{N}^{\circ}$ 263/20I5 defendem a implementação de sistemas de tratamento e 
JÚNIOR, A. P. M.; CarValho, R. P. B.; Facury, D. M.; CAMILO, G. A.; RAMANery,G.S.

MINERODUTOS E IMPLICAÇÕES SOCIOAMBIENTAIS: PANORAMA LEGAL E REFLEXÕES PARA O CENÁRIO DE MINAS GERAIS

reuso das águas captadas para os minerodutos, de forma a reduzir as demandas por abastecimento, as pressões sobre os mananciais e, consequentemente, os riscos de escassez hídrica. Entretanto, o cumprimento de tais normas ainda não é exigido uma vez que permanecem em tramitação na Assembleia do Estado. Assim, até o momento, as águas utilizadas nos minerodutos não são tratadas e não retornam para os cursos d'água, para que possam ser reutilizadas à montante. O recurso, ainda que em cenários de ameaças de escassez, tem sido totalmente inutilizado e descartado no litoral brasileiro após o transporte do minério.

Outra pauta que acirra a discussão sobre os minerodutos é o fato de que apenas um único usuário da água venha a ter a concessão de uso de grande parte do volume disponível. Isso fere o direito de acesso a usos múltiplos dos recursos hídricos superficiais, o que é agravado devido à mineração não se enquadrar como um tipo de uso prioritário, como é o caso do uso doméstico e da dessedentação de animais (BRASIL, I997).

O mineroduto é considerado um modal seguro e de baixo risco de acidentes. No entanto, alguns eventos marcaram o cenário ambiental recente de Minas Gerais, causando contaminação de cursos d'água e consequentes impactos na biota e nos sistemas municipais de abastecimento. Dois vazamentos foram noticiados pela mídia no mineroduto da Samarco. Em 2008, vazaram I.890 $\mathrm{m}^{3}$ de polpa de minério em Anchieta (ES), enquanto em 20I0, um vazamento em Espera Feliz (MG) liberou um volume de $433 \mathrm{~m}^{3}$, causando mortandade de peixes e interrompendo a captação de água do município por três dias (BERTONI; AMÂNCIO, 20I5). Nesses casos, a Samarco foi multada pelo IBAMA.

Outros dois rompimentos ocorreram no mineroduto da Anglo American em Santo Antônio do Grama (MG), nos dias I2 e 29 de março de 2018 . No total, 480 toneladas de polpa de minério atingiram o ribeirão Santo Antônio, afluente do rio Doce, interrompendo a captação de água para abastecimento doméstico e causando impactos no ecossistema fluvial. A Anglo American passou por seis meses de paralisação e concedeu férias coletivas aos funcionários de todo o Complexo Minero-Portuário (ANGLO AMERICAN, 20I8). Esses eventos denotam que existe certa imprevisibilidade nos minerodutos em termos de riscos ambientais, trazendo insegurança hídrica e acirramento de disputas pelo uso da água nos municípios e bacias em que os modais se localizam. 


\section{Considerações finais}

As escolhas envolvendo os minerodutos perpassam por processos decisórios que devem valorizar o caráter complexo, multidisciplinar e sinérgico em termos socioambientais. Os interesses do poder público, do setor minerário e da sociedade civil não são sempre convergentes e as tensões e conflitos têm mais chances de serem lapidados a partir de processos decisórios participativos.

A análise das implicações socioambientais dos minerodutos deve envolver a logística, a engenharia e a apuração técnica da conformidade e da mitigação de impactos ambientais, bem como a compatibilização dos múltiplos interesses de usos da água e da terra. Também cabe ressaltar a necessidade de que a análise dos impactos ambientais seja realizada considerando os efeitos sinérgicos e cumulativos nos sistemas físicos e sociais durante os processos de licenciamento, tendo em vista o complexo minerário como um todo. As elevadas demandas hídricas intrínsecas ao funcionamento dos minerodutos em Minas Gerais implicam a necessidade de disponibilização e outorgas de volumes de água que podem impactar outros usos e a qualidade ambiental nas bacias hidrográficas. Como consequências, tensões, conflitos e até mesmo desastres ambientais associados à segurança hídrica podem ocorrer, seja envolvendo aspectos de qualidade ou de quantidade de recursos hídricos. Esse contexto explicita a importância da participação informada da sociedade, que deve opinar nos processos de planejamento dos minerodutos, dado os riscos de comprometimento do seu patrimônio natural e, particularmente, de geração de cenários de insegurança hídrica. Representantes da sociedade civil, devidamente informados e empoderados, podem contribuir com os debates e tomada de decisões. 


\section{Referências}

ALMG - Assembleia Legislativa de Minas Gerais. Deputado pede prazo para analisar PL sobre mineroduto. 29 maio 20I9. Disponível em: https://www.almg.gov.br/acompanhe/noticias/ arquivos/20I9/05/28_CCJ_projeto_retorno_agua_minerodutos.html. Acesso em: 5 ago. 2019.

ALMG. Projeto de Lei $\mathbf{n}^{\circ} \mathbf{I . 2 2 I}$, de $\mathbf{2} 8$ de abril de 20I5. Obriga as mineradoras do Estado que possuem sistema de mineroduto a retornar toda a água utilizada ao local de que foi retirada, devidamente tratada. Minas Gerais, Disponível em: https://www.almg.gov.br/atividade_parlamentar/tramitacao_ projetos/texto.html?a=20I5\&n=I22I\&t=PL. Acesso em: I4 nov. 2019.

AMPLO Consultoria. RIMA - EIA Integrado do Complexo do Germano. Belo Horizonte, [s. $n$.], 2017. I5O p.

ANA - AGÊNCIA NACIONAL DE ÁGUAS. Resolução n 72, de 20 de março de 20I2. Brasília, 2012. I p.

ANGLO AMERICAN. Nota à imprensa - férias coletivas no Minas-Rio / information note. [S.l.]: I6 abr. 20I8. Disponível em: https://brasil.angloamerican.com/pt-PT/imprensa/noticias/2018/16-04-2018. Acesso em 23 jun. 2016.

ANGLO AMERICAN. Sistema Minas-Rio. Unidade de Negócio Minério de Ferro do Brasil. Ago. 20I5. Disponível em: https://brasil.angloamerican.com/ $/$ media/Files/A/Anglo-American-Group/ Brazil/imprensa/fact-sheets/folder-minas-rio-agosto-de-20I5.pdf. Acesso em: io jul. 20 I9.

ANM - AGÊNCIA NACIONAL DE MINERAÇÃO. Decreto $\mathbf{n}^{\circ} \mathbf{9 \cdot 4 0 7}$, de $\mathbf{1 2}$ de junho de $20 \mathrm{I} 8$. Regulamenta o disposto no inciso VII do $\int 2^{\circ}$ e no $\int 5^{\circ}$ do art. $2^{\circ}$ da Lei $n^{\circ} 8.00 \mathrm{I}$, de I3 de março de I990. Brasília, 20I8. Disponível em: https://www.planalto.gov.br/ccivil_03/_ato20I5-20I8/20I8/ decreto/d9407.htm. Acesso em: 05 fev. 2019 .

ANM - AGÊNCIA NACIONAL DE MINERAÇÃO. Lista dos Municípios afetados pela atividade de mineração beneficiários de parcela da CFEM. Brasília, 20I9. Disponível em: http://www.anm.gov. br/assuntos/cfem-municipios-afetados/versao-final_lista-provisoria-dos-municipios-afetados-pelaatividade-de-mineracao-beneficiarios-de-parcela-da-cfem. Acesso em: II mar. 2020.

ANTT - AGÊNCIA NACIONAL DE TRANSPORTES TERRESTRES. Dutovias. Disponível em: http://geo.antt.gov.br/dutovias/. Acesso em: 22 jun. 2020.

BERTONI, E.; AMÂNCIO, T. Samarco teve outros 4 vazamentos antes de tragédia em MG. Folha de São Paulo, São Paulo, o2 dez. 2015. Disponível em: https://wwwi.folha.uol.com.br/ cotidiano/20I5/I2/I7I3745-samarco-teve-outros-4-vazamentos-de-lama-antes-de-trajedia-em-mg. shtml. Acesso em: ig jul. 20I9. 
BRANDT Meio Ambiente. Estudo de Impacto Ambiental. Sul Americana de Metais. Projeto Bloco 8.

Capítulo 3 - Informações Gerais. [S.l.:s.n.], 2019. 74 p.

BRANDT Meio Ambiente. Mineroduto Minas Rio. Relatório de Impacto Ambiental. [S.l...s.n.], 2006. $93 \mathrm{p}$.

BRASIL. Lei 6.938, de 3I de agosto de I98I. Dispõe sobre a Política Nacional do Meio Ambiente, seus fins e mecanismos de formulação e aplicação, e dá outras providências. Disponível em: http://www. planalto.gov.br/ccivil_03/LEIS/L6938.htm. Acesso em: II mar. 2020

BRASIL. Lei 9.433, de o8 de Janeiro de I997. Institui a Política Nacional de Recursos Hídricos, cria o Sistema Nacional de Gerenciamento de Recursos Hídricos, regulamenta o inciso XIX do art. 2I da Constituição Federal, e altera o art. Iffl da Lei nffl 8.00I, de I3 de março de I990, que modificou a Lei nffl 7.990, de 28 de dezembro de i989. Disponível em: http://www.planalto.gov.br/ccivil_03/LEIS/ L9433.htm. Acesso em: 16 dez. 2019.

CANOFRE, F. Samarco, responsável por barragem de Mariana, recebe licença para voltar a operar. Folha de São Paulo, São Paulo, 25 out. 20I9. Disponível em: https://wwwi.folha.uol.com.br/ cotidiano/20I9/Io/samarco-responsavel-por-barragem-de-mariana-recebe-licenca-para-voltar-aoperar.shtml. Acesso em: 03 nov. 2019.

CAXITO, F.; DIAS, T. G.. Ferro. In: PEDROSA-SOARES, A. C.; VOLL, E.; CUNHA, E. C. Recursos Minerais de Minas Gerais. Belo Horizonte: CODEMGE, 20I8. 36 p.

CEPED/RS-UFRGS - Centro Universitário de Estudos e Pesquisas sobre Desastres da Universidade Federal do Rio Grande do Sul. Capacitação em gestão de riscos. Porto Alegre: UFRGS, 20I6, 270p.

DNPM - Departamento Nacional de Produção Mineral. Anuário Mineral Brasileiro - Principais Substâncias Metálicas -20I6. Brasília: DNPM, 20I8. 33 p.

ECOPLAN; LUME. Plano Integrado De Recursos Hídricos Da Bacia Hidrográfica Do Rio Doce. Volume I - Relatório Final. [S.l.:s.n.], 2010. 66 p.

GESTA - Grupo de Estudos em Temáticas Ambientais. Parecer sobre o Mineroduto Morro do Pilar/ MG a Linhares/ES. Belo Horizonte: Observatório dos Conflitos Ambientais no Estado de Minas Gerais, 20I4. I4O p.

GOOGLE EARTH PRO. Imagem de satélite do Córrego do Galo, município de Pedra Dourada, Minas Gerais (2I maio 20I9.). [S.l.]: Google Earth, 20I9. Data de visualização: 23 jun. 2020.

GOOGLE EARTH PRO. Imagem de satélite do Córrego do Galo, município de Pedra Dourada, Minas Gerais (05 set. 20II.). [S.l.]: Google Earth, 20II. Data de visualização: 23 jun. 2020. 
IBGE - Instituto Brasileiro de Geografia e Estatística. Contas econômicas ambientais da água: Brasil 20I3-20I5. Brasília: IBGE, 20I5. Disponível em: https://www.ibge.gov.br/estatisticas/economicas/ contas-nacionais.html. Acesso em: 26 ago. 2019.

IPT - Instituto de Pesquisas Tecnológicas. Avaliação técnica das condições de integridade e de gestão de riscos do mineroduto do sistema Minas-Rio - Etapa I. [São Paulo]: IPT, 20I8. Disponível em: https:// brasil.angloamerican.com/ /media/Files/A/Anglo-American-Group/Brazil/sustentabilidade/meioambiente/parecer-tecnico-ipt-21079-30I.pdf. Acesso em: 23 jun. 2020.

MINAS GERAIS. Lei N Lei nffl I3.I99, de 29 de janeiro de I999. Dispõe sobre a Política Estadual de Recursos Hídricos e dá outras providências. Disponível em: http://www.siam.mg.gov.br/sla/ download.pdf?idNorma=5309. Acesso em: i6 dez. 2019 .

MINAS GERAIS. Dados Gerais. Atualizado em o6 maio 20I9. Disponível em: https://www.mg.gov. br/conteudo/conheca-minas/geografia/dados-gerais. Acesso em: 20 jan. 2020.

MLOG. Our Companies. Disponível em: https://www.ri.mlog.com.br/our-companies. Acesso em: 27 jan. 2019 .

MOSAIC Fertilizantes informa que barragens de Tapira e Araxá voltaram a operar em plena capacidade. Grupo Globo, [S.l.], o5 set. 20I9. Disponível em: https://gi.globo.com/mg/triangulomineiro/noticia/2019/o9/05/mosaic-fertilizantes-informa-que-barragens-de-tapira-e-araxavoltaram-a-operar-em-plena-capacidade.ghtml. Acesso em: o2 out. 2019

MOSAIC. The Mosaic Company. Disponível em: http://www.mosaicco.com/index.htm. Acesso em: 27 jan. 2019 .

MTPA - MINISTÉRIO DOS TRANSPORTES, PORTOS E AVIAÇÃO CIVIL. ANUÁRIO ESTATÍSTICO DE TRANSPORTES (20I0-20I7). Brasília: Portos e Aviação Civil, 20I8. 5I p.

PASINI, I. L. P.; OLIVEIRA, M. L. R.; FONSECA, B. C. Mineroduto é progresso? Conflito socioambiental no município de Viçosa - MG. ACTA Geográfica, Boa Vista, v. 7, n. I5, p.I33-I5I, 2013.

PESSOA, T. A. LOGÍSTICA BRASILEIRA: um estudo teórico do Modal Dutoviário. 20i6. 76 f. Monografia (Graduação) - Curso de Administração, Departamento de Administração, Universidade Federal da Paraíba, João Pessoa, 20ı6.

PIZARRO, L. Ferrous desiste de licenciamento para mineroduto. Jornal O TEMPO, Belo Horizonte, II ago. 20i6. Disponível em: https://www.otempo.com.br/economia/ferrous-desiste-de-licenciamentopara-mineroduto-I.I353332. Acesso em: 02 out. 2019.

RIBEIRO, G. C. Expansão da fronteira minerária: estratégias de negociação de terras para implantação de mineroduto no município de Ferros, Minas Gerais. Revista Política e Planejamento Regional, Rio de Janeiro, v. 4, n. I, p. 75 a 95, janeiro/junho 2017. 
RIBEIRO, J.; LEMOS, R.; COTA, G.; MAGALHÃES JR., A. P.. A abordagem de conflitos pelo uso da água na gestão de recursos hídricos - Reflexões a partir do contexto da Bacia do Alto Rio das Velhas/ MG. Caminhos de Geografia, Uberlândia, v. I6, n. 68, p. 343-36I, 2018.

SAM - Sul Americana de Metais. A SAM. Disponível em: https://www.sammetais.com.br/a-sam/. Acesso em: 27 jan. 2019 .

SAMARCO. Relatório Anual de Sustentabilidade 20I4. [Belo Horizonte]: [s.n.], 20I5. 8I p. Disponível em: https://www.samarco.com/relatorios/. Acesso em: o9 jul. 2019.

SAMPAIO, D. A.; BRANDÃO, P. R. G. Propriedades Reológicas De Concentrados De Minérios De Ferro Da Samarco Mineração S.A. E Seu Efeito No Potencial De Entupimento Do Mineroduto. In: Encontro Nacional de Tratamento de Minérios e Metalurgia Extrativa, I9., Recife, Pernambuco, 2002. Anais... Recife: [s.n.], 2002.

SANTOS, R. L. C.; SOBRAL, L. G. S.; ARAÚJO, R.V.V.; FOSFERTIL. Produção de fosfato no Brasil: Complexo De Mineração De Tapira / Fosfertil. In: Encontro Nacional de Tratamento de Minérios e Metalurgia Extrativa, I9., Recife, Pernambuco, 2002. Anais... Recife: [s.n.], 2002.

SISEMA - Sistema Estadual de Meio Ambiente e Recursos Hídricos - Minas Gerais. IDESisema. Atualizado em 20 abr. 2020. Disponível em: http://idesisema.meioambiente.mg.gov.br/. Acesso em 23 jun. 2020.

SNIS - Sistema Nacional de Informações sobre Saneamento. Série Histórica - Municípios. Disponível em: http://app4.cidades.gov.br/serieHistorica/\#. Acesso em: 26 ago. 2019.

SOUSA, D. R. N.; OLIVEIRA, M. L. R. Processo de cooperação como ferramenta de organização entre grupos atingidos por grandes empreendimentos: o caso do mineroduto da Ferrous na microrregião de Viçosa - MG. Redes (St. Cruz Sul, Online), [S.l.], v. 20, n. 2, p. 33 6 - 359, maio/ago. 2015.

SUPRAM JEQUITINHONHA. PARECER ÚNICO Nffl 05807I5/20I8 (SIAM), de I6/08/20I8. Diamantina, 20I8. I8 p.

VALE conclui venda de ativos de fertilizantes para a Mosaic. Grupo Globo, [S.l.], o9 jan. 2018. Disponível em: https://gi.globo.com/economia/noticia/vale-conclui-venda-da-vale-fertilizantespara-a-mosaic.ghtml. Acesso em: ro jul. 2019

VALE. Fato Relevante - Aquisição da SAMITRI. [S.l.], 30 maio 2000. Disponível em: http://www. vale.com/brasil/pt/investors/information-market/press-releases/paginas/fato-relevante-aquisicaoda-samitri.aspx. Acesso em: 28 jan. 2019. 